\title{
Formulation and Evaluation of Paracetamol Loaded Mucoadhesive Microspheres
}

\section{Nethaji Ramalingam ${ }^{* 1}$, Shahana Parvin ${ }^{1}$, Binulal $C^{1}$, Manikandan Palanivelu ${ }^{1}$, N. Subramaniam Surendiran', Babu Ganesan²}

${ }^{1}$ Department of Pharmaceutics, Devaki Amma Memorial College of Pharmacy, Chelembra-673634, Malappuram, Kerala, India.

${ }^{2}$ Department of Pharmaceutical Chemistry, Devaki Amma Memorial College of Pharmacy, Chelembra-673634, Malappuram, Kerala, India.

*Corresponding author: Nethaji Ramalingam, Department of Pharmaceutics, Devaki Amma Memorial College of Pharmacy, Chelembra-673634, Malappuram, Kerala, India, E-mail: nethajijkkncp32@gmail.com

Received: March 20, 2017; Revised: March 31, 2017; Published: April 10, 2017

Copyright: (C2017 Nethaji R, et al. This is an open-access article distributed under the terms of the Creative Commons Attribution License, which permits unrestricted use, distribution, and reproduction in any medium, provided the original author and source are credited. The article has been previewed and authenticated by the Authors before sending the publication for print. The Journal, Editor and the Editorial Board are not entitled or liable to either justify or responsible for inaccurate and misleading data if any. It is the sole responsibility of the Author concerned.

Citation: Nethaji R, Shahana P, Binulal C, et al. Formulation and Evaluation of Paracetamol Loaded Mucoadhesive Microspheres. Int J Pharm Pharmacol 2017; 1: 106. doi: 10.31531/25813080.1000106

\footnotetext{
Abstract

Objective: The present work is to formulate the mucoadhesive microspheres loaded Paracetamol using two different natural gums with an aim to increase the GI retention time, enhance bioavailability over prolonged period of time in the stomach and upper GIT and decreased GI side effect.

Methods: Paracetamol mucoadhesive microspheres were formulated using sodium alginate, different concentration of Xanthan gum and Guar gum by ionic gelation technique. Six formulations were prepared and evaluated for relevant parameters.

Results: Percentage yield is found between $52.34 \pm 0.58 \%$ to $84.21 \pm 0.21 \%$ in all formulations. The surface morphology of microspheres was characterized by SEM; it was discrete, spherical in shape and showed free flowing properties. The mean particle size of microspheres significantly increases and it was the range between $37.05 \pm 0.05 \mu \mathrm{m}$ to $45.29 \pm 0.06 \mu \mathrm{m}$. Among all the formulations, XG-III showed a high entrapment efficiency is $94.80 \pm 0.54 \%$ and highest percentage sorption in distilled water is observed. The in-vitro drug release studies revealed that XG-III is controlled and found to be $77.04 \pm 0.22 \%$ at the end of the dissolution studies. The mechanism of drug release was evaluated using the linear regression coefficient. Stability studies of selected mucoadhesive microspheres showed good results. It could be also concluding that the all the formulations were shown satisfactory results and suitable for potential therapeutic uses.

Keywords: Paracetamol, Mucoadhesive microspheres, Xanthan gum, Guar gum, In-vitro evaluation, Stability studies
} 


\section{Introduction}

Development of oral controlled release formulations is an attempt to release drug slowly and control manner into gastro intestinal tract (GIT) and maintain an effective drug concentration in the systemic circulation for longer time. But several physiological difficulties such as inability to restrain and locate within the desired region of the GIT due to variable gastric emptying and motility are observed. Furthermore, due to short residence time through the major absorption zone, can results incomplete drug release lead to reduced therapeutic efficacy of an administered dose and eliminated quickly from the blood circulation therefore bioavailability of drug also suffers [1-3]. In order to avoid this variability, efforts have been made to increase and prolonged gastric retention time by using oral controlled drug delivery system with gastro retentive properties which remain at the absorption site for an extended period of time. It can be achieved by coupling mucoadhesion characteristics to microspheres which has efficient absorption and enhanced bioavailability of drugs due to a high surface to volume ratio, a much more intimate contact with the mucus layer, specific targeting to the absorption site results an improved therapeutic effect for gastric diseases, ex. liver damage and peptic ulceration [4]. Paracetamol is a mild "aniline" analgesic with weak COX enzyme inhibiting activity which used as analgesic and antipyretic. The onset of an action is approximately $11 \mathrm{~min}$ after oral administration, and the limitation is short biological half-life $(2-3 \mathrm{~h})$. It has rapidly absorbed from small intestine and fast metabolize and about $98 \%$ of the drug gets eliminated after a single oral dose (500 mg every 4-6 h), thus requiring a high frequency dosing (3-4 times/day) [5-8] for maintain the plasma level and an acute overdoses of paracetamol can cause potentially fatal liver damage [9]. Also, Paracetamol tablet gets rapidly absorbed from small intestine following an oral route and produce gastro intestinal toxicity following repeated dose administration. So, it's necessary to develop mucoadhesive microspheres from naturally occurring polymers, which adhere to the mucosa, prolong gastric residence time, enhance bioavailability and maintain constant drug levels for extended period with decrease Nethaji R, et al. Int J Pharm Pharmacol dosing frequency and reduces dose related toxicity such as peptic ulceration and liver damage compared than conventional oral dosage forms. The objective of the present work is to formulate the Paracetamol loaded mucoadhesive microspheres using two different natural gums with varying drug - polymer ratios and to evaluate the microspheres characterization.

\section{Materials and Methods}

\section{Materials}

Paracetamol was obtained from Yarrow Chem Products, Mumbai, India. Sodium alginate and xanthan gum from Qualigens Fine Chem Pvt Ltd, Mumbai, India, Guar gum from Yarrow Chem Products, Mumbai, India, Calcium chloride from Flora Chemicals, India.

\section{IR Spectral Analysis}

FT-IR spectrum of Paracetamol and polymers was recorded using $\mathrm{KBr}$ mixing method on the FT-IR instrument (Schimadzu FTIR instrument). The drug alone and drug in combination with polymers in the ratio of $1: 1$ was taken and subjected to FT-IR studies [10].

\section{Preparation of Mucoadhesive Microspheres of Paracetamol}

The Microspheres were prepared according to the ionotropic gelation method by using different ratios of Paracetamol (PCT), sodium alginate, guar gum and xanthan gum. Sodium alginate was dissolved in deionized water to form a homogeneous solution $(2 \% \mathrm{w} / \mathrm{v})$. Guar gum and xanthan gum were dissolved separately with deionized water to get viscous and sticky solutions. The pure drug was dispersed in the solution of gum and then sodium alginate solution was added to it with vigorous stirring until formation of an even dispersion. The resulting dispersion was then extruded drop wise into the $100 \mathrm{ml}$ calcium chloride solution $(10 \% \mathrm{w} / \mathrm{v})$ through a $23 \mathrm{G}$ syringe. The formed beads were retained in the calcium chloride solution for 15 mins to complete the formation of spherical rigid microspheres. They were collected by decantation, washed and dried at room 
temperature and subsequently stored in desiccators. Six formulations were prepared by different ratios of drug and polymer as given in Table 1 and were evaluated for relevant parameters [11].

\section{Characterization of Mucoadhesive Microspheres}

\section{Micromeritic Properties}

Mucoadhesive microspheres were characterized by their micromeritic properties like bulk density, tapped density, Carr's index, Hausner's ratio and angle of repose [12-15].

\section{Percentage Yield}

The prepared microspheres were collected, dried at room temperature and then weighed. The percentage yield of the microspheres was calculated by measured weight of prepared microspheres was divided by the total amount of all excipients and drug used [16]. Percentage yield (\%) is estimated by

Amount of microspheres obtained $(\mathrm{g})$

$=\frac{\text { Theoretical amount }(\mathrm{g})}{\mathrm{X}} 100$

\section{Determination of Particle Size}

The prepared mucoadhesive microspheres were selected randomly and their size was measured by optical microscopy (Olympus, India) method [17-19].

\section{Entrapment Efficiency}

The calculated amount of the microspheres was taken and the drug was extracted from the microspheres by crushing the microspheres using mortar and pestle. $25 \mathrm{mg}$ of this powder were added to the $100 \mathrm{ml}$ phosphate buffer $(\mathrm{pH}$ 7.4) followed by stirring of the solution at 1000 $\mathrm{rpm}$ for $3 \mathrm{~h}$. After that, the solution was filtered and the filtrate was analyzed spectrophotometrically at $249 \mathrm{~nm}$ [20]. The Percentage entrapment efficiency is calculated by:

$=\frac{\text { Estimated percent drug content }}{\text { Theoretical percent drug content }}$

X 100

\section{In-Vitro Drug Release Studies}

Nethaji R, et al. Int J Pharm Pharmacol
It was carried in USP XXI paddle type dissolution test apparatus using phosphate buffer ( $\mathrm{pH}$ 7.4) as dissolution medium, volume of dissolution medium was $900 \mathrm{ml}$ and temperature was maintained at $37 \pm 0.5^{\circ} \mathrm{C}$ throughout the study. Paddle speed was adjusted to $50 \mathrm{rpm}$. An interval of 30 minutes, $5 \mathrm{ml}$ of sample was withdrawn with replacement of $5 \mathrm{ml}$ fresh medium and analyzed for drug content by UV Visible spectrophotometer at $249 \mathrm{~nm}$. All the experimental units were analyzed in triplicate and cumulative percentage drug release was calculated [21]. To understand the mechanism and kinetics of in-vitro drug release studies of all formulations was subjected to goodness of fit test by linear regression analysis, according to Zero order and First order kinetics equations, Higuchi's and Korsmeyer-Peppa's model [2223].

\section{Sorption Studies}

The calculated quantity of dried microspheres from each batch was placed in two different media such as distilled water and $0.1 \mathrm{~N} \mathrm{HCl}$ $(100 \mathrm{ml}$ each) and it was kept at room temperature. At end of $48 \mathrm{~h}$, measured the increase in weight and find percent water sorption by the following formula [24]. Percent water sorption is determined by

$=\left(\mathrm{W}_{\mathrm{s}}-\mathrm{W}_{\mathrm{d}}\right) / \mathrm{W}_{\mathrm{d}} \mathrm{x} 100$

$\mathrm{W}_{\mathrm{s}}=$ weight of swollen device,

$\mathrm{W}_{\mathrm{d}}=$ weight of dry device

\section{Stability Studies}

Best formulations were placed in borosilicate screw capped glass containers and stored in room temperature $\left(27 \pm 2{ }^{\circ} \mathrm{C}, 60 \pm 5 \% \mathrm{RH}\right)$ and stability chamber $\left(45 \pm 2^{\circ} \mathrm{C}, 70 \pm 5 \% \mathrm{RH}\right)$ which was maintained at 90 days under ICH and WHO guidelines to assess their stability. At the end of specified day's period, samples were withdrawn and are analyzed for their drug content [25].

\section{Morphological Studies}

Surface morphology of the selected mucoadhesive microspheres of paracetamol were determined by using Scanning Electron Microscopy (JEOL, JSM-6701 F, JAPAN) operating at $15 \mathrm{KV}$ [26]. 


\section{Results and Discussion}

\section{IR Spectral Analysis}

FT-IR spectra of prepared sample were taken in the wavelength region was $400-4000 \mathrm{~cm}^{-1}$ at ambient temperature and the resolution was 4 $\mathrm{cm}^{-1}$ and compared the position and relative intensity of absorption band of physical admixtures (PSX \& PSG) and pure drug was shown in Figure 1, Figure 2 and Figure 3. From the results, IR spectrum of pure drug was found to be similar to the standard IR spectrum which indicates that the obtained sample was pure Paracetamol. The IR spectra of all the pure samples and Paracetamol physical admixtures of suitable proportion of polymers were subjected to the study. From the results, it has been observed that the characteristic $\mathrm{C}-\mathrm{H}$ stretching, $\mathrm{C}=\mathrm{O}$ stretching, $\mathrm{C}=\mathrm{C}$ stretching, $\mathrm{NH}$ bending, $\mathrm{C}-\mathrm{OH}$ stretching of pure Paracetamol drug was unchanged in the spectra of Paracetamol physical admixtures and indicated that there was no significant difference in the IR spectra of pure drug compare with physical admixtures and with no changes in the peak shape and no shift of peaks. It is concluded that the characteristics bands of Paracetamol were not affected after loading polymer microspheres and the drug was compatible with the polymers and were expected to stable during the encapsulation process because there were no significant interactions between the drug and polymers in the physical admixtures.

\section{Micromeritic Properties}

From Table 2 stated that the bulk density and tapped density lies in between 0.6150 to 0.7709 and 0.6486 to $0.8578 \mathrm{~g} / \mathrm{cm}^{3}$ indicate good packing of the microspheres. The Carr's index was lies between $5.18 \%$ to $10.13 \%$ indicating excellent flow characteristics. The Hausner's ratio was lies between 0.898 to 0.948 indicate good flow. Also, it was observed that the angle of repose is found to be less than $40^{\circ}$ indicate free and good flow properties of microspheres.

\section{Percentage Yield, Particle Size and Drug Entrapment}

From Table 3, the percentage yield is found between $52.34 \%$ to $84.21 \%$ in all formulations and it was observed that, the concentration of polymer increased, the percentage yield of the Nethaji R, et al. Int J Pharm Pharmacol mucoadhesive microspheres was also slightly increased. The average particle size found in between $37.05 \pm 0.05$ to $45.29 \pm 0.0 .06 \mu \mathrm{m}$. As the drug to polymer ratio was increased the mean particle size of microspheres were also increased. The significant increase in particle size may be because of the increase in the viscosity of droplets which formed larger droplets and consequently larger microspheres due to increase in concentration of polymer solution. From the results, the entrapment efficiency was found to be in the range $44.28 \%$ to $94.80 \%$. A maximum of $94.8 \%$ of drug entrapped in XG-III mucoadhesive microsphere which was prepared by xanthan gum batches. It was observed that the entrapment efficiency increase with increasing the polymer concentration. Also, the particle size increases more drug will be bound in the microspheres leading to increased entrapment efficiency.

\section{In-Vitro Drug Release Studies}

The in-vitro drug release profile of all batches of microspheres was studies using Phosphate buffer ( $\mathrm{pH}$ 7.4). The comparative in-vitro drug release curve was found in Figure 4 and Figure 5 and shows that the drug release from XG-III formulation is found $77.04 \%$; similarly, GG-III formulation was $80.28 \%$ at the end of dissolution studies. From the results, it was observed that, the in-vitro performance of mucoadhesive microspheres show prolonged and controlled release of paracetamol due to the increasing the level of polymer concentration leads to increased density of polymer matrix into the microspheres which results in increased diffusional path length. This may decrease the drug release from the polymer matrix and exhibit prolonged time. In order to understand the mechanism and kinetics of invitro drug release studies of all formulations are given in Table 4 and coefficient of correlation (r) values were computed. From the results, zero order kinetics was found to be 0.9901, $0.9952,0.9908$, \& $0.9911,0.9916,0.9948$ respectively. So, the co-efficient of determination indicated that the release data was best fitted with zero order kinetics. When the drug release data was put in to Higuchi's equation, good correlation coefficient (r) values 0.9789 to 0.9899 were obtained, indicating the drug release was diffusion controlled release mechanism. The release data obtained were 
also put in Korsmeyer-Peppas model in order to find out $\mathrm{n}$ values, which describe the drug release mechanism. From the kinetics result data, the ' $n$ ' values of mucoadhesive microspheres were found in the range of 0.8675 to 1.0567 with correlation coefficient values ranging from 0.9502 to 0.9972 , indicating good linearity. Hence, the above observations, the release of drug from mucoadhesive microspheres provide a controlled release for a period of sufficient hours and the kinetics study shows that ' $r$ ' values of all formulated batches indicate compliance with Higuchi's plot and reveals that the drug release follows nonfickian diffusion mechanism.

\section{Sorption Studies}

From Table 5 the percentage water sorption behavior of best formulations (XG-III and GGIII) was determined in distilled water and $0.1 \mathrm{~N}$ $\mathrm{HCl}$. The percentage water sorption of mucoadhesive microspheres is found in distilled water ranges from $18.20 \%$ to $84.80 \%$ and $17.04 \%$ to $72.40 \%$ in $0.1 \mathrm{~N} \mathrm{HCl}$ at the end of $48 \mathrm{~h}$. From the results, it was observed that sorption behavior indicates that the microspheres exhibit excellent sorption in distilled water which may be attributed to the pores and cavities present in them. Formulation GG-I showed least percentage sorption in both media and XG-III which shows highest sorption in distilled water $(84.80 \%)$ and in $0.1 \mathrm{~N}$ $\mathrm{HCl}(72.40 \%)$. The fundamentals that increase in degree of sorption depends on polymer concentration in formulations. From the results, it was observed that the xanthan gum formulations showed greater percentage of sorption than guar gum batches.

\section{Stability Studies}

Best formulation of Paracetamol microspheres (XG-III) based upon in-vitro drug release studies was taken and stored at room temperature and in stability chamber and analyzed for their drug content and illustrated in Table 6. From the results shows that there is about $64.28 \%$ to $65.98 \%$ of drug present in XG-III formulation with no observable physical changes occur during the storage period for three months.

\section{Morphological Studies}

The surface morphology was determined by SEM for the characterization of shape and size of mucoadhesive microspheres. Figure 6 and Figure 7 shows that the prepared microspheres is completely covered with the mucoadhesive polymer and were a good specificity, spherical, uniform in shape and exhibited smooth surface. The surface smoothness of prepared microspheres was decreased by increasing the amount of gum which confirmed by SEM.

\section{Conclusion}

Mucoadhesive microspheres loaded Paracetamol is obtained by using suitable ratios of Xanthan gum and Guar gum and the formulated microspheres might be better practical approach to achieve the retarded effect and continuously releasing the medication over extended period of time in the stomach and upper GIT with decreased GI side effect due to the less frequently of administration and all the result data were found to be satisfactory. Hence, it's concluded that the prepared mucoadhesive microspheres can be selected for the development of gastro retentive drug delivery system for potential therapeutic uses, thereby enhance bioavailability and improve the patient compliance.

\section{Conflict of Interest}

The authors declare no conflict of interest.

\section{Acknowledgements}

The authors are thankful to the Management, Devaki Amma Memorial College of Pharmacy, Chelembra, Malapuram District, Kerala, for providing support and necessary facilities to carry out this research work.

\section{References}

1. Rouge N, Buri P, Doelker E. Drug absorption sites in the gastrointestinal tract and dosage forms for site specific delivery. Int J Pharm 1996; 136: 117-139. 
2. Sanjay G, Shringi S. Gastroretentive Drug Delivery Systems. Pharmatech: Business Briefing 2003; 160-166.

3. Shah SH, Patel JK, Patel NV. Stomach specific floating drug delivery system: A review. Int J PharmTech Res 2009; 1: 623633.

4. Vasir JK, Tambwekar K, Garg S. Bioadhesive microspheres as a controlled drug delivery system. Int J Pharm 2003; 255: 13-32.

5. Jamil S. Kohli K, Khar RK, et al. Sustained release sodium alginate microspheres formulation of aceclofenac and paracetamol as potential combination therapy in arthritis. J Pharm Pharmacol. 2007; 59: 117.

6. Aslani P, Kennedy RA. Effect of gelation conditions and dissolution media on the release of paracetamol from alginate gel beads. J Microencapsul 1996; 13: 601-614.

7. Kubo.W, Miyazaki S, Attwood D. Oral Sustained delivery of Paracetamol from in situ-gelling gellan and Sodium alginate formulations. Int J Pharm 2003; 258: 55-64.

8. Endo H, Watanabe Y, Matsumoto M, et al. Preparation and Evaluation of heat sensitive melting gel-acetaminophen gel. Jap J Hosp Pharm 2000; 26: 250-258.

9.Tripathy KD. Essential of Medical Pharmacology. Jaypee Brothers Medical Publishers (P) Ltd, New Delhi, 2003; $5^{\text {th }}$ ed, 181-182.

10. Ichikawa M, Watanabe S, Miyake Y. New Multiple-Unit Oral Floating Dosage Systems, I: Preparation and In-vitro Evaluation of Floating and SustainedRelease Characteristics. J Pharm Sci 1991; 80: 1062-1066.

11. Mankala SK, Nagamalli NK, Raprla R, et al. Preparation and characterization of mucoadhesive microcapsules of gliclazide with natural gums. S J Pharm Sci 2011; 4: $38-48$.

12. Aulton ME. Pharmaceutics: The Science of Dosage Form Design. Livingstone C, Elsevier Science Ltd 2002; $2^{\text {nd }}$ ed. 315-320.

13. Gupta GD, Garg R. Gastro-retentive Floating Microspheres of Silymarin: Preparation and in-vitro Evaluation. Trop J Pharm Res 2010; 9: 59-66.

14. Trivedi P, Verma ML, Garud N. Preparation and Characterization of
Aceclofenac microspheres. Asian J Pharmacol 2008; 110-115.

15. Krogel I, Bodmeir R. Floating or pulsatile drug delivery system based on coated effervescent cores. Int J Pharm 1999; 187: 175-84.

16. Nath B, Nath LK, Mazumdar B, et al. Preparation and in-vitro evaluation of gastric floating microspheres of Metformin HCl. Indian J Pharm Edu Res 2009; 43: 177-186.

17. Upadhye K, Bakhle S, Dixit G. Preparation and evaluation of gelatin microspheres containing Ciprofloxacin hydrochloride. Ind Drugs 2004; 41: 665-668.

18. Yang Z, Song B, Li Q, et al. Preparation of microspheres with micro balloons inside for floating drug delivery systems. J Appl Polym Sci 2004; 94: 197-202.

19. Giovanni FP, Giulia B, Piera DM, et al. Microencapsulation of semisolid of ketoprofen microspheres. Int $\mathrm{J}$ Pharm. 2002; 5: 134-144.

20. Kashyap P, Dhongade H, Singh K, et al. Preparation and Evaluation of Acetaminophen Microparticles. Int J Med Pharm Sci 2011; 1.

21. Patil SS, Kasture PV. Design and Evaluation of biodegradable Poly L-Lactide microsphere of Aceclofenac. J Pharm Research. 2007; 6: 24-28.

22. Yadav A, Jain DK. Formulation and Evaluation of mucoadhesive microspheres of Propranolol hydrochloride for sustained drug delivery. Asian J Pharm Med Sci 2011; 1 : 3.

23. Dandangi PM, Manvi FV, Gadad AP, et al. Microencapsulation of verapamil hydrochloride by Ionotropic gelation technique. Indian J Pharm Sci 2004; 66: 631-635.

24. Olalla JA, Guranacy RA. Polymers for mucosal delivery swelling and mucoadhesive evaluation. Indian drugs 2002; 39: 270-276.

25. Shankar NB, Kumar NU, Balakrishna PK. Formulation design, preparation and invitro evaluation of Mucoadhesive microcapsule employing control release polymers to enhance gastro-retention for oral delivery of Famotidine. IJPSR 2009; 2: 22-29. 
26. Sahoo SK, Mallik AA, Barik BB. eudragit microspheres of Stavudin. Trop J Formulation and in-vitro evaluation of

Table 1: Composition of Paracetamol mucoadhesive microspheres

\begin{tabular}{|c|c|c|c|c|c|}
\hline $\begin{array}{c}\text { Formulations } \\
\text { Code }\end{array}$ & $\begin{array}{c}\text { Paracetamol } \\
(\mathbf{m g})\end{array}$ & $\begin{array}{c}\text { Sodium } \\
\text { Alginate } \\
(\boldsymbol{\%} \mathbf{w} / \mathbf{v})\end{array}$ & $\begin{array}{c}\text { Guar } \\
\mathbf{G u m} \\
(\boldsymbol{\%} \mathbf{w} / \mathbf{v})\end{array}$ & $\begin{array}{c}\text { Xanthan } \\
\mathbf{G u m} \\
(\boldsymbol{\%} \mathbf{w} / \mathbf{v})\end{array}$ & $\begin{array}{c}\text { Calcium } \\
\text { Chloride } \\
(\% \mathbf{w} / \mathbf{v})\end{array}$ \\
\hline XG-I & 500 & 10 & - & 1.25 & 50 \\
\hline XG-II & 500 & 10 & - & 2.5 & 50 \\
\hline XG-III & 500 & 10 & - & 3.75 & 50 \\
\hline GG-I & 500 & 10 & 1.25 & - & 50 \\
\hline GG-II & 500 & 10 & 2.5 & - & 50 \\
\hline GG-III & 500 & 10 & 3.75 & - & 50 \\
\hline
\end{tabular}

Table 2: Micromeritic properties data of Paracetamol mucoadhesive microspheres

\begin{tabular}{|c|c|c|c|c|c|}
\hline $\begin{array}{c}\text { Formulations } \\
\text { Code }\end{array}$ & $\begin{array}{l}\text { Bulk Density } \\
\qquad\left(\mathrm{g} / \mathrm{cm}^{3}\right)\end{array}$ & $\begin{array}{c}\text { Tapped Density } \\
\qquad\left(\mathrm{g} / \mathrm{cm}^{\mathbf{3}}\right)\end{array}$ & $\begin{array}{c}\text { Carr's } \\
\text { Index }(\%)\end{array}$ & $\begin{array}{c}\text { Hausner's } \\
\text { Ratio }\end{array}$ & $\begin{array}{c}\text { Angle of } \\
\text { Repose }(\theta)\end{array}$ \\
\hline XG-I & $0.6150 \pm 0.02$ & $0.6486 \pm 0.07$ & $5.18 \pm 0.05$ & $0.948 \pm 0.09$ & $29^{0} .85^{\prime} \pm 0.45$ \\
\hline XG-II & $0.6228 \pm 0.07$ & $0.6774 \pm 0.09$ & $8.06 \pm 0.11$ & $0.920 \pm 0.04$ & $30^{0} .20^{\prime} \pm 0.29$ \\
\hline XG-III & $0.6499 \pm 0.03$ & $0.7185 \pm 0.05$ & $9.54 \pm 0.09$ & $0.899 \pm 0.31$ & $32^{0} .64^{\prime} \pm 0.38$ \\
\hline GG-I & $0.7225 \pm 0.05$ & $0.7724 \pm 0.03$ & $6.46 \pm 0.07$ & $0.935 \pm 0.11$ & $28^{0} .32^{\prime} \pm 0.42$ \\
\hline GG-II & $0.7685 \pm 0.04$ & $0.8461 \pm 0.01$ & $9.17 \pm 0.33$ & $0.908 \pm 0.42$ & $30^{0} .80^{\prime} \pm 0.35$ \\
\hline GG-III & $0.7709 \pm 0.07$ & $0.8578 \pm 0.09$ & $10.13 \pm 0.12$ & $0.898 \pm 0.15$ & $31^{0} .37^{\prime} \pm 0.23$ \\
\hline
\end{tabular}

Results are mean $\pm S D$ of three trials $(n=3)$

Table 3: Percentage yield, Particle size and Drug entrapment of Paracetamol mucoadhesive microspheres

\begin{tabular}{|c|c|c|c|}
\hline $\begin{array}{c}\text { Formulations } \\
\text { Code }\end{array}$ & Percentage Yield $(\boldsymbol{\%})$ & $\begin{array}{c}\text { Particle Size } \\
(\boldsymbol{\mu m})\end{array}$ & Drug Entrapment $(\boldsymbol{\%})$ \\
\hline XG-I & $68.48 \pm 0.83$ & $38.23 \pm 0.05$ & $51.34 \pm 0.25$ \\
\hline XG-II & $76.61 \pm 0.64$ & $42.35 \pm 0.09$ & $68.98 \pm 0.56$ \\
\hline XG-III & $84.21 \pm 0.21$ & $45.29 \pm 0.06$ & $94.80 \pm 0.54$ \\
\hline GG-I & $52.34 \pm 0.58$ & $37.05 \pm 0.05$ & $44.28 \pm 0.21$ \\
\hline GG-II & $74.61 \pm 0.90$ & $41.17 \pm 0.07$ & $62.15 \pm 0.67$ \\
\hline GG-III & $82.05 \pm 0.42$ & $43.52 \pm 0.09$ & $86.24 \pm 0.19$ \\
\hline
\end{tabular}

Results are mean $\pm S D$ of three trials $(n=3)$ 
Table 4: Kinetic analysis data of Paracetamol mucoadhesive microspheres

\begin{tabular}{|c|c|c|c|c|c|c|c|c|}
\hline $\begin{array}{c}\text { Formulations } \\
\text { Code }\end{array}$ & \multicolumn{9}{|c|}{ Zero Order } & \multicolumn{2}{c|}{ First Order } & \multicolumn{2}{c|}{$\begin{array}{c}\text { Higuchi's } \\
\text { Model }\end{array}$} & \multicolumn{2}{c|}{$\begin{array}{c}\text { Korsmeyer and } \\
\text { Peppa's Model }\end{array}$} \\
\cline { 2 - 9 } XG-I & 0.9901 & 8.9480 & 0.9474 & -0.0991 & 0.9833 & 38.64 & 0.9791 & 0.8675 \\
\hline XG-II & 0.9952 & 8.6372 & 0.9616 & -0.0786 & 0.9899 & 97.33 & 0.9960 & 0.9776 \\
\hline XG-III & 0.9908 & 8.3495 & 0.9648 & -0.0661 & 0.9789 & 35.96 & 0.9502 & 1.1002 \\
\hline GG-I & 0.9911 & 9.1155 & 0.9164 & -0.1086 & 0.9822 & 39.33 & 0.9748 & 0.8702 \\
\hline GG-II & 0.9916 & 8.7716 & 0.9640 & -0.0847 & 0.9888 & 37.96 & 0.9943 & 0.9258 \\
\hline GG-III & 0.9948 & 8.5377 & 0.9645 & -0.0720 & 0.9865 & 36.84 & 0.9722 & 1.0567 \\
\hline
\end{tabular}

Table 5: Sorption ability of Paracetamol mucoadhesive microspheres

\begin{tabular}{|c|c|c|}
\hline Formulations Code & In Distilled Water (\%) & In 0.1 HCl (\%) \\
\hline XG-I & $36.60 \pm 0.04$ & $24.80 \pm 0.03$ \\
\hline XG-II & $49.20 \pm 0.02$ & $30.20 \pm 0.02$ \\
\hline XG-III & $84.80 \pm 0.03$ & $72.40 \pm 0.06$ \\
\hline GG-I & $18.20 \pm 0.06$ & $17.04 \pm 0.01$ \\
\hline GG-II & $32.40 \pm 0.08$ & $24.40 \pm 0.05$ \\
\hline GG-III & $52.80 \pm 0.02$ & $42.01 \pm 0.02$ \\
\hline
\end{tabular}

Results are mean $\pm S D$ of three trials $(n=3)$

Table 6: Stability studies data of Paracetamol mucoadhesive microspheres (XG III)

\begin{tabular}{|c|c|c|c|}
\hline \multirow{2}{*}{$\begin{array}{c}\text { At the end } \\
\text { (in days) }\end{array}$} & \multirow{2}{*}{$\begin{array}{c}\text { Physical } \\
\text { Appearance }\end{array}$} & \multicolumn{2}{|c|}{ Percentage Drug Content } \\
\cline { 3 - 4 } & & $\mathbf{2 7} \pm \mathbf{2}^{\mathbf{0}} \mathbf{C}, \mathbf{6 0} \pm \mathbf{5 \%} \mathbf{R H}$ & $\mathbf{4 0} \pm \mathbf{2}^{\mathbf{0}} \mathbf{C}, \mathbf{7 0} \pm$ \\
$\mathbf{5 \%} \mathbf{R H}$
\end{tabular}

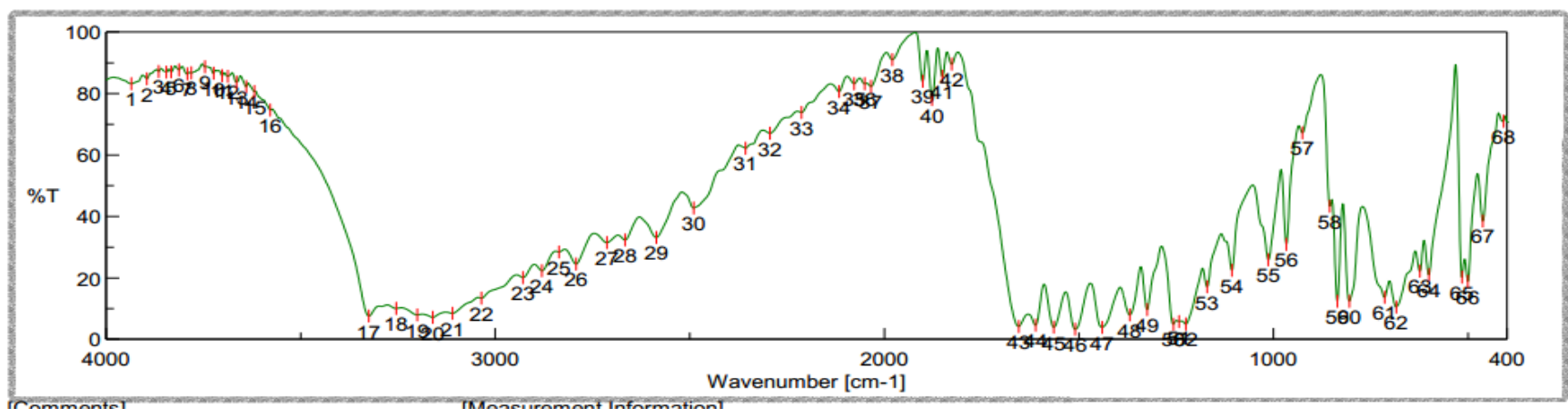

Figure 1: IR spectra of pure Paracetamol 


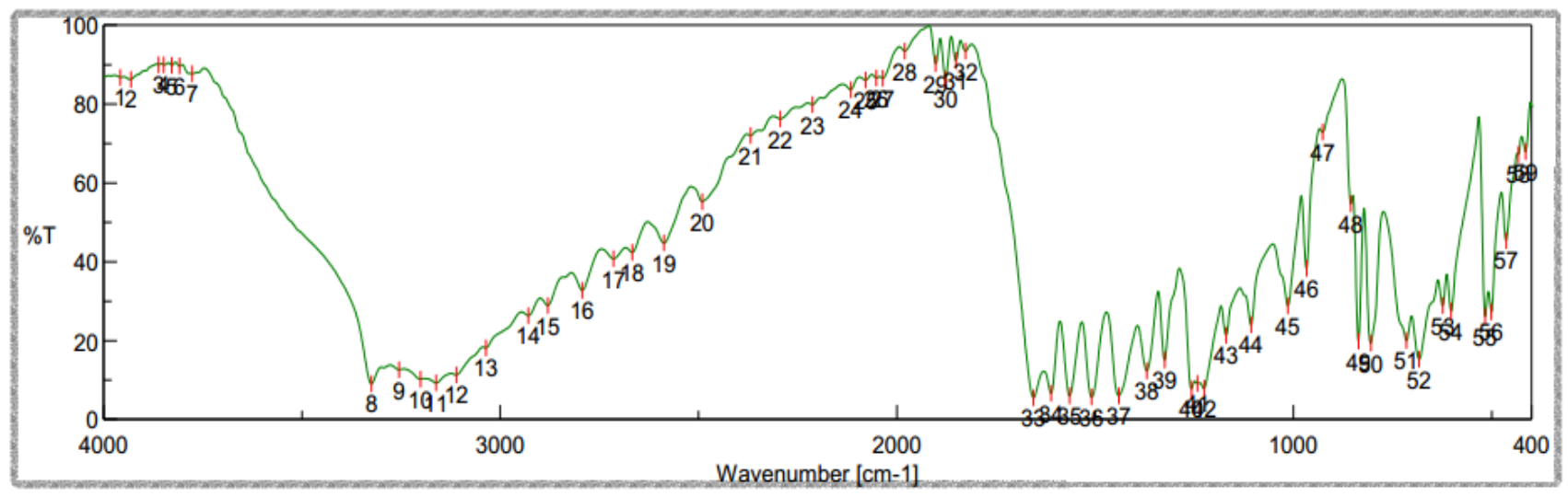

Figure 2: IR spectra studies of physical admixtures of Paracetamol, sodium alginate and xanthan gum (PSX)

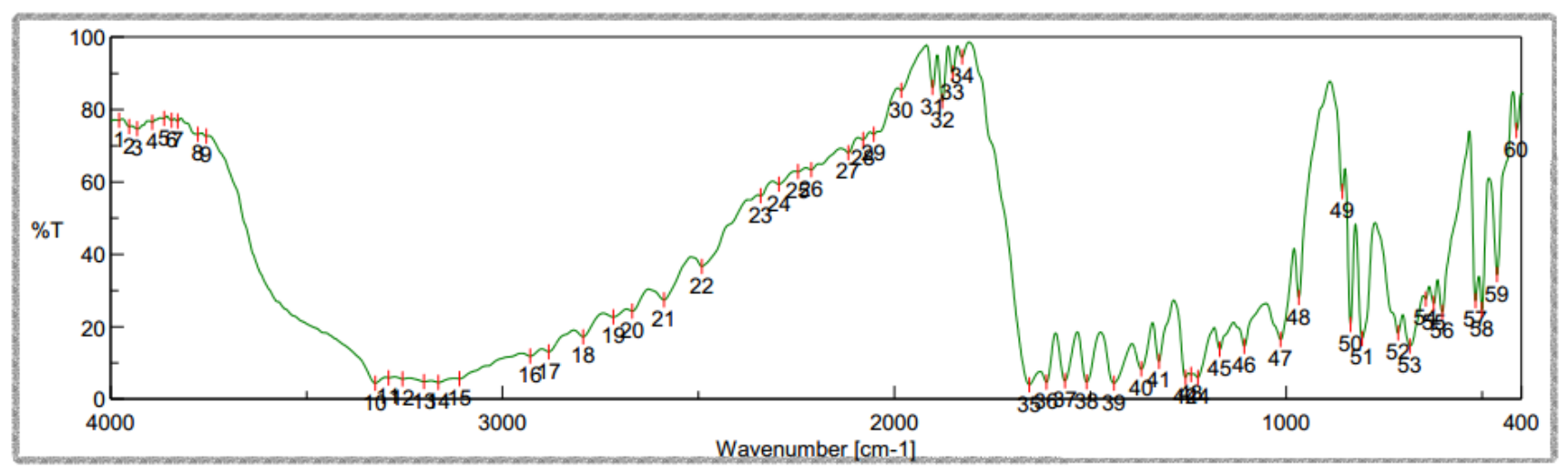

Figure 3: IR spectra studies of physical admixtures of Paracetamol, sodium alginate and guar gum (PSG)

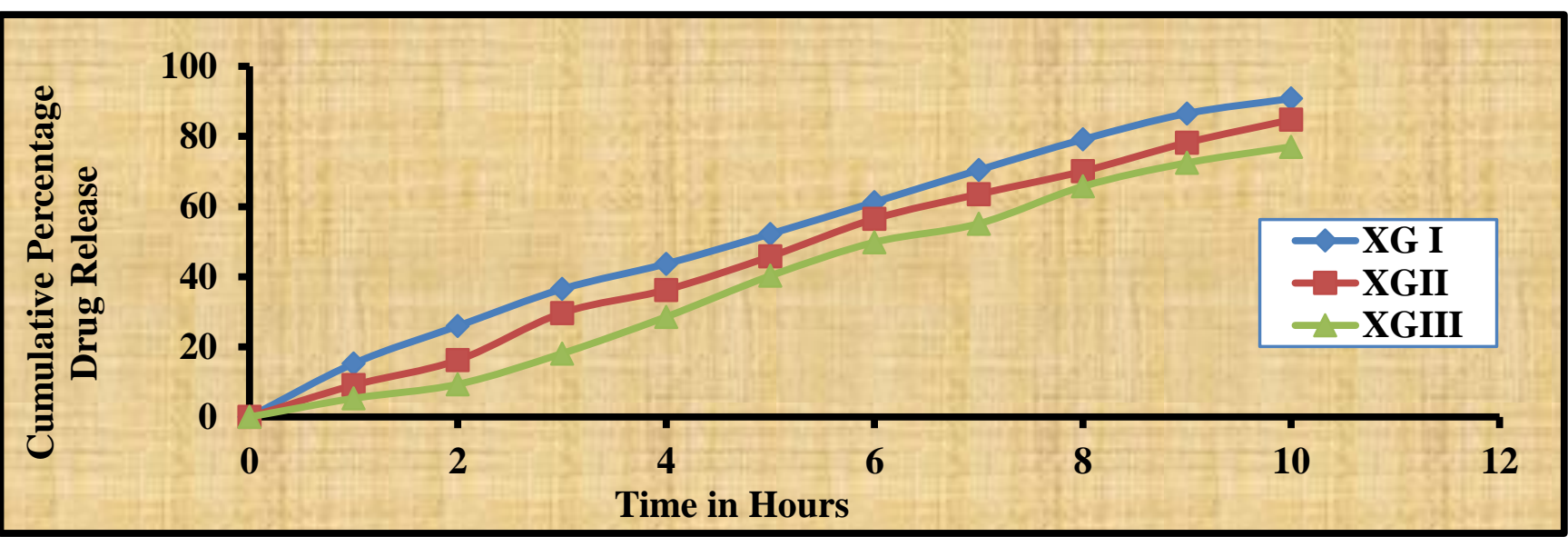

Figure 4: Comparative in-vitro drug release plot of Paracetamol mucoadhesive microspheres (XG-I to XG-III) 


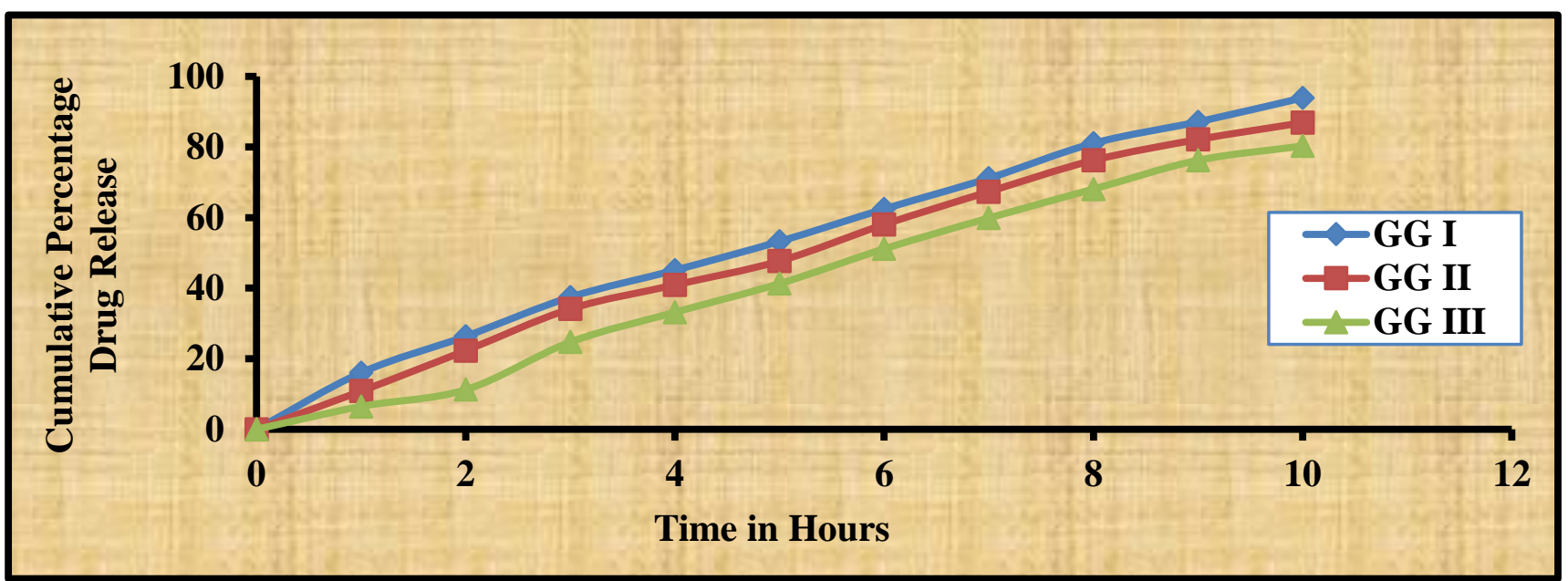

Figure 5: Comparative in-vitro drug release plot of Paracetamol mucoadhesive microspheres (GG-I to GG-III)

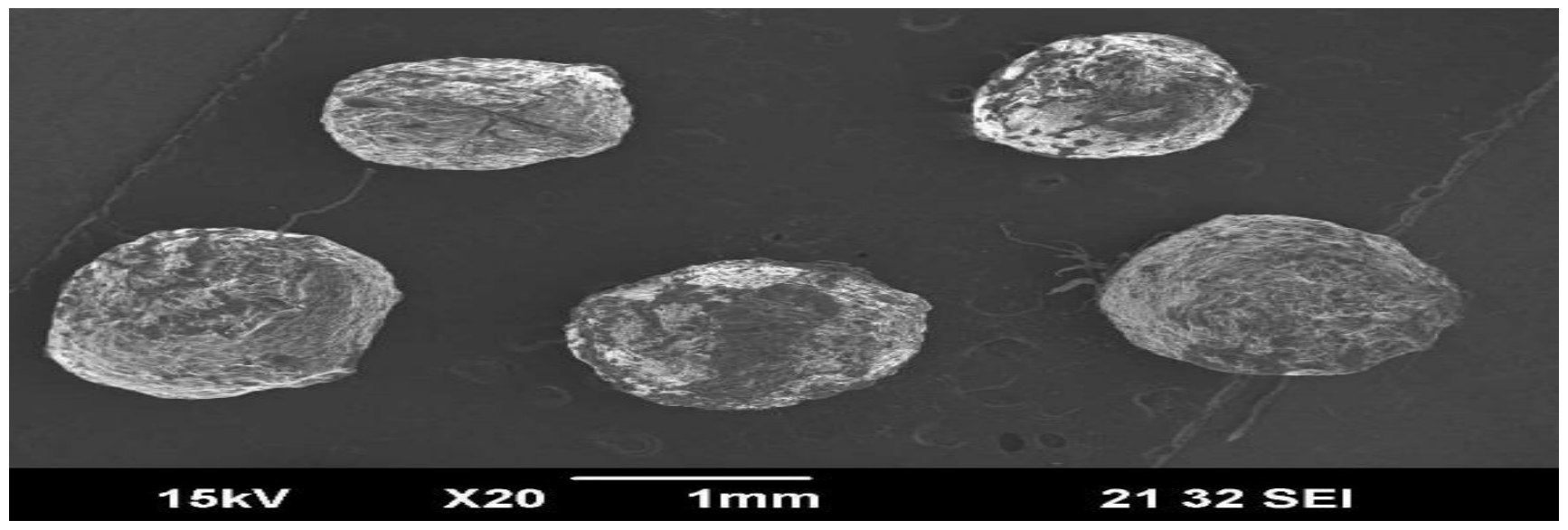

Figure 6: SEM image of Paracetamol mucoadhesive microspheres (XG-III)

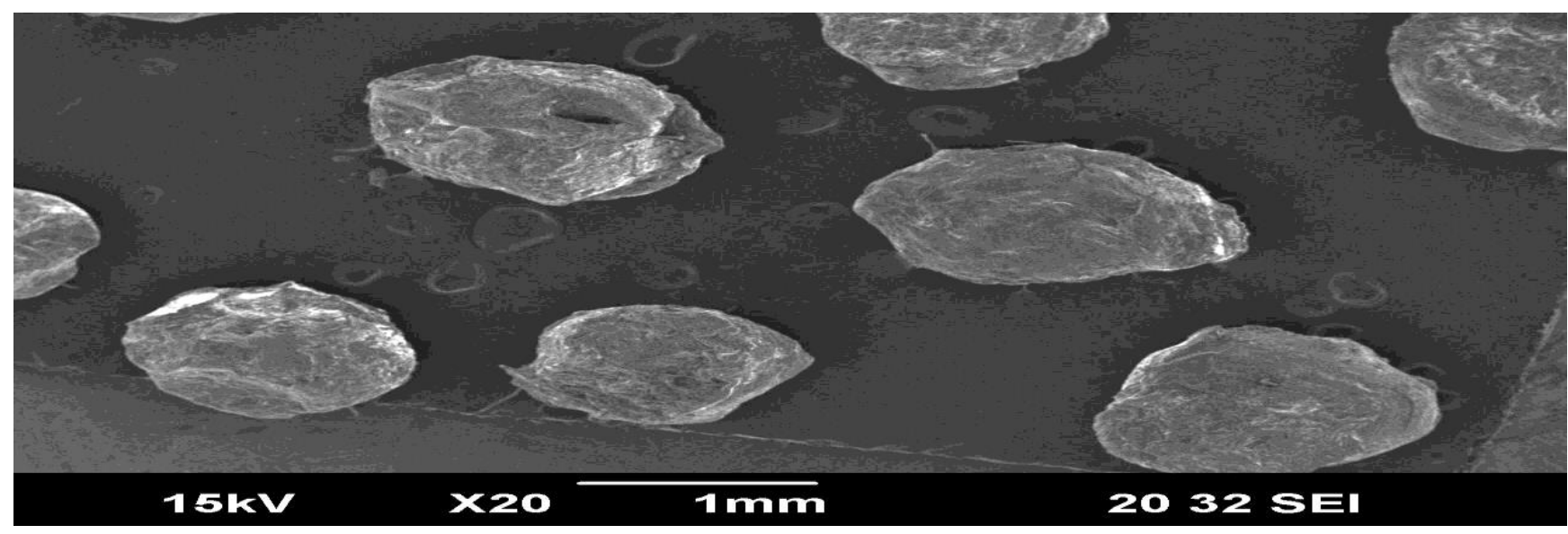

Figure 7: SEM image of Paracetamol mucoadhesive microspheres (GG-III) 
This manuscript was peer-reviewed

Mode of Review: Single-blinded

Editor: Dr. Syed Sarim Imam

International Journal of Pharmaceutics and Pharmacology is an open access, peer reviewed journal published by Edwiser International.

Submit your valuable manuscript at-

editor.ijpp@edwiserinternational.com

submit.manuscript@edwiserinternational.com

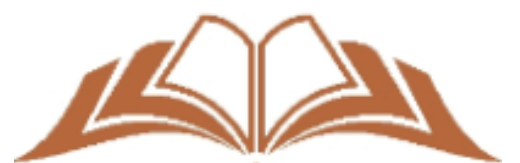

EDW $\mathrm{D}$ S E R
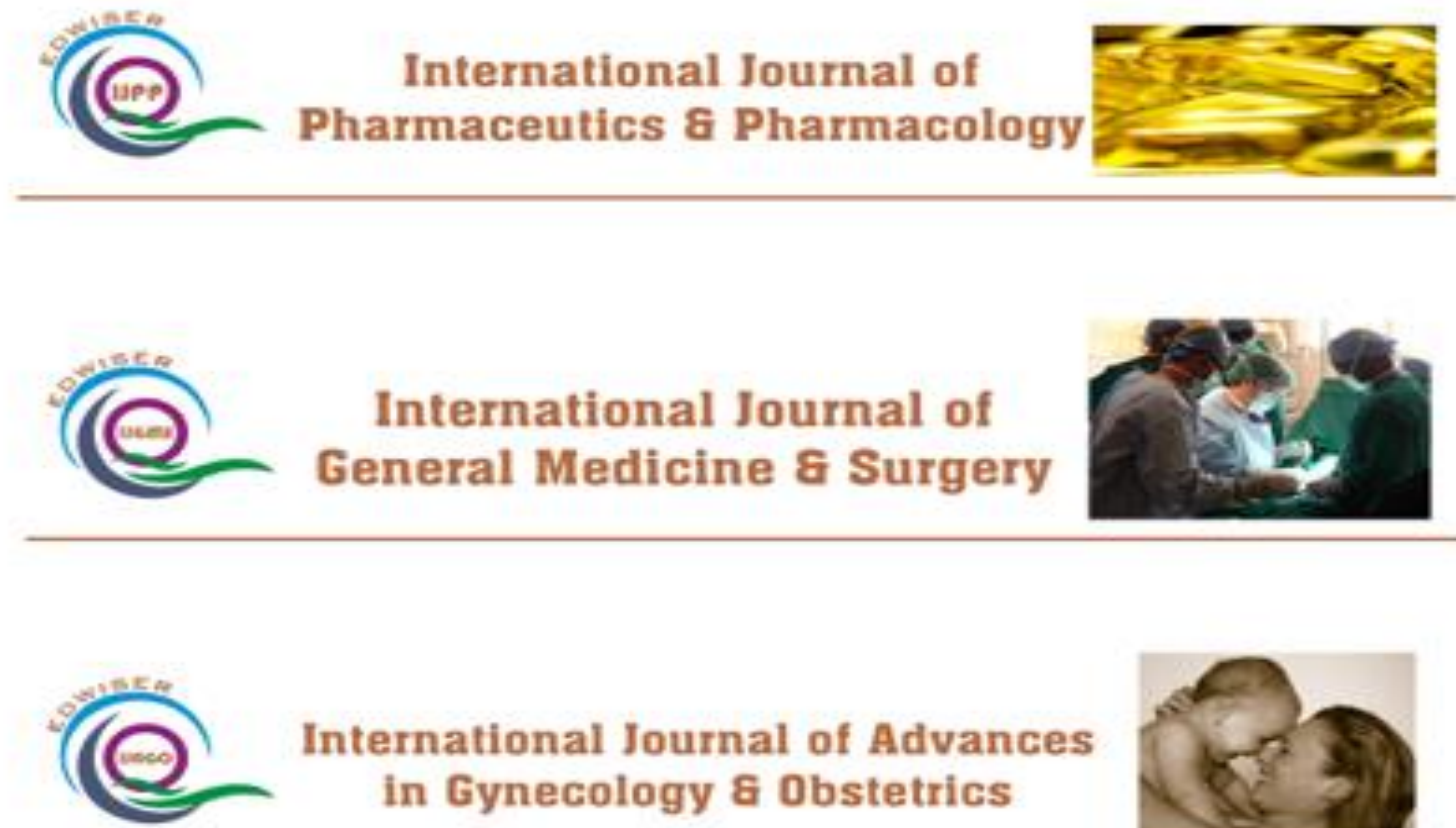

International Journal of Advances in Gynecology 8 Obstetrics
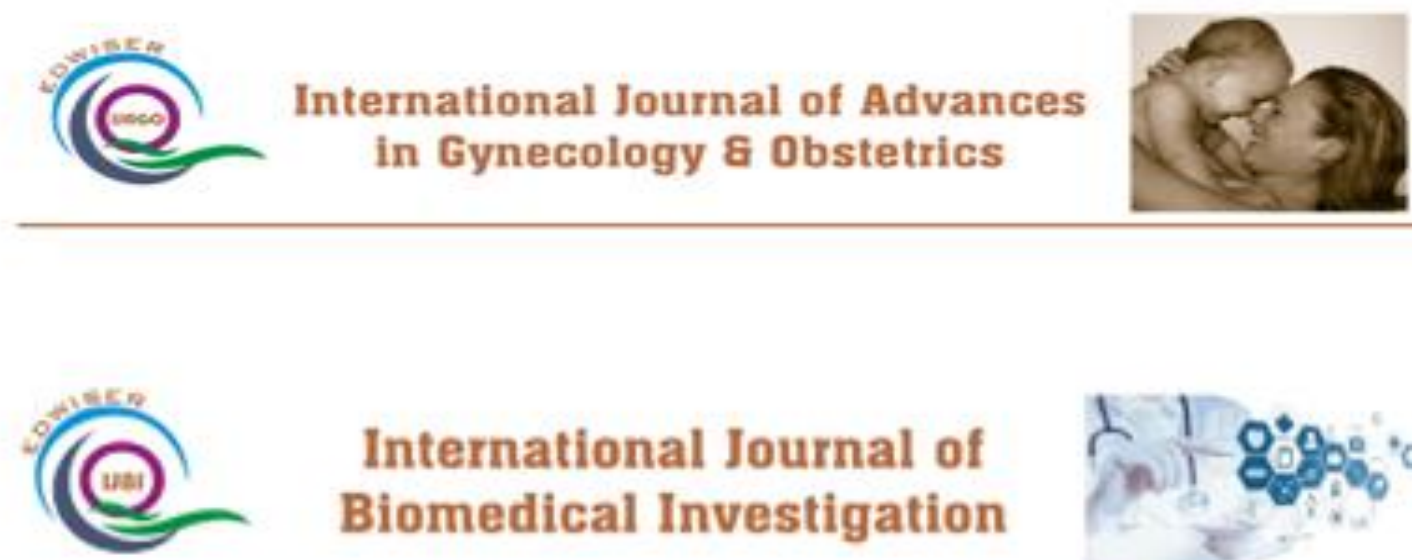

\section{International Journal of} Biomedical Investigation
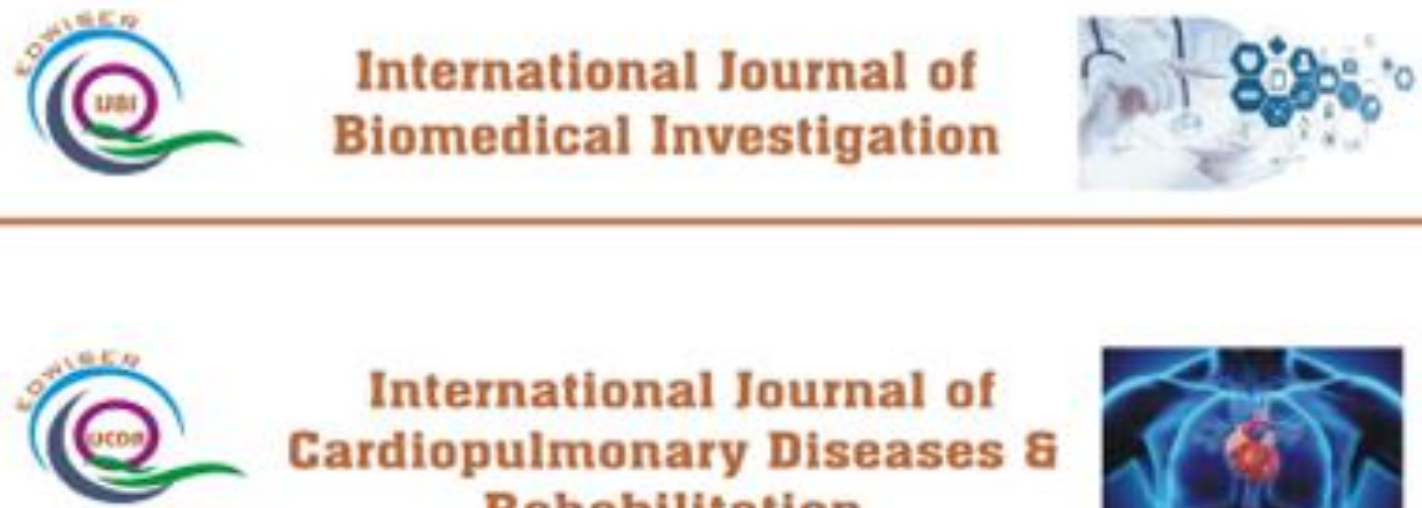

\section{International Journal of Cardiopulmonary Diseases \& Rehabilitation}

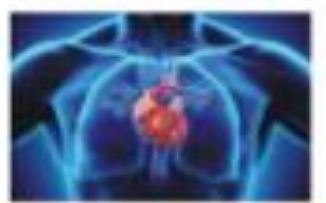

